\title{
Characterization of a Novel Curcumin based Schiff base Ligand, Synthesized by Microwave Method
}

\author{
BEENA KUMARI K. S. ${ }^{1 *}$, SUDHA DEVI R. ${ }^{2}$ and NAYANA SENAN V. ${ }^{2}$ \\ 'Department of Chemistry, All Saints' College, University of Kerala, Thiruvananthapuram, \\ Kerala-695007, India. \\ ${ }^{2}$ Post Graduate and Research Centre, Mahatma Gandhi College, Thiruvananthapuram, \\ Kerala-695004, India. \\ ${ }^{*}$ Corresponding author E-mail: beenagireesh@yahoo.co.uk
}

http://dx.doi.org/10.13005/ojc/370630

(Received: November 02, 2021; Accepted: December 03, 2021)

\begin{abstract}
A new Schiff base ligand derived from curcumin and ethylenediamine has been synthesized by the microwave irradiation method. The synthesized ligand was characterized by using FT-IR, UV-Vis, Molar conductance, NMR, PL and DLS studies. The results confirmed that the successful formation of Curcumin Based Schiff Base ligand. The ligand synthesized was stable at room temperature, completely soluble in hot methanol/DMF, partially soluble in ethanol/DMSO/acetone and insoluble in water. The spectra studies of FTIR and UV-Visible confirmed the formation of the azomethine group in the ligand. NMR spectrum confirmed the presence of aromatic proton, hydroxyl proton, amine proton etc in the ligand. The luminescent property of the ligand was confirmed by the photoluminescence spectroscopic method. The low molar conductance value showed the non-electrolytic nature of the ligand. The dynamic light scattering studies showed that the ligand synthesized was in nanometer scale. The structure of the ligand was also proposed based on the analysis reports.
\end{abstract}

Keywords: Curcumin, Ethylenediamine, Photoluminescence, Microwave irradiation, Schiff base.

\section{INTRODUCTION}

The Schiff base ligands are extensively attracted by researchers due to its wide applications in various fields including biochemical, analytical, medicinal and antimicrobial fields ${ }^{1}$. Schiff base ligand unveiled a high tendency towards complex formation with metals ${ }^{2}$. An immense number of Schiff base complexes have potential biological interest and are used as successful models of biological compounds. Schiff base is a nitrogen parable of an aldehyde or ketone in which the $\mathrm{C}=\mathrm{O}$ group is replaced by the $\mathrm{C}=\mathrm{N}-\mathrm{R}$ group ${ }^{3}$. The formation of a Schiff base from aldehyde or ketone is a reversible reaction and normally takes place under acid or base catalysis. The presence of a lone pair of electrons in $\mathrm{SP}^{2}$ hybridized orbital of the nitrogen atom of the azomethine group imparts excellent chelating ability of the Schiff base ligand ${ }^{4}$. Microwave-assisted synthesis is emerging as a new and extremely attractive method in the area of inorganic synthesis ${ }^{5}$. Microwave synthesis has

This is an Open Access article licensed under a Creative Commons license: Attribution 4.0 International (CC- BY). Published by Oriental Scientific Publishing Company @ 2018 
become one of the most exclusive methods for the synthesis of ligand and metal complexes due to the shorter reaction time, providing high temperature for reaction, less usage of solvent, better yield and fewer pollution rates ${ }^{6,7}$. Presently green chemistry gets more importance in chemical synthesis due to the easy availability of raw materials, eco-friendly nature and cost-effectiveness. Present work focused to develop a new Schiff base ligand from curcumin and ethylenediamine. Curcumin, the main bioactive component present in turmeric (Curcuma longa) has been known for its medicinal activity and also showed potent coordination ability with metals $^{8}$. The highly conjugated diketone moiety makes curcumin an excellent chelating ligand ${ }^{9}$. The $\beta$-diketone group present in curcumin dispense in condensation reactions, including Schiff base reaction ${ }^{10}$. Ethylenediamine was an amine having two free amino groups that easily forms a Schiff base with carbonyl compounds.

\section{EXPERIMENTAL}

Preparation of the ligand CL.4,4'-((1E, 3Z,5Z,6E)5-((2-aminoethyl)imino)-3-hydroxyhepta-1,3,6triene-1,7-diyl) bis (2-methoxyphenol)

All reagents and solvents were purchased from Sigma-Aldrich and of AR grade. The curcumin derived Schiff base ligand (CL) was prepared by the condensation reaction of curcumin with a primary amine under microwave irradiation method. 0.3683 $\mathrm{g}(0.001 \mathrm{~mol})$ of curcumin was added with $6 \mathrm{~mL}$ hot methanol and shaken well for complete dissolution. To this solution add a drop of glacial acetic acid and 3 $\mathrm{mL}$ methanolic solution of ethylenediamine. Then the mixture was placed in the microwave oven (model no: MC28H5015VB) for irradiation at $400 \mathrm{~W}$ for $5 \mathrm{~min}$ and then allowed to cool at room temperature. The dark reddish solid precipitate obtained was filtered, washed with $1: 1$ methanol/water, dried under $60^{\circ} \mathrm{C}$ in a hot oven and stored in silica desiccators.

\section{Infrared Spectroscopic Analysis}

The FT-IR spectra were recorded on a Perkin Elmer Spectrum 100 FTIR spectrophotometer by using a $\mathrm{KBr}$ disc. The recorded FTIR spectra range was $4000-450 \mathrm{~cm}^{-1}$.

\section{Electronic Spectra}

Electronic spectra were recorded on Perkin Elmer Lambda-2B 365 spectrophotometer. The spectra were taken by using methanol as solvent at $25^{\circ} \mathrm{C}$ using $1 \mathrm{~cm}$ quartz cell in the range $200-800 \mathrm{~nm}$.

\section{${ }^{1} \mathrm{H}$ NMR}

${ }^{1} \mathrm{H}$-NMR spectra were recorded in methanol medium on a PROBHD Z108618_0948 (PULPROG), 400MHZ spectrometer.

\section{Melting point}

The melting points were determined on the Veego instrument (Model REC2203882) using standard paraffin melting method where the sample is melted in a capillary tube and noted the melting point.

\section{Molar Conductance}

Molar conductance measurement of $10^{-3} \mathrm{M}$ solutions of the ligand in DMF was carried out by using Systronic conductivity meter 306 at room temperature. The cell constant of the conductivity meter was $1.02 \mathrm{~cm}^{-1}$.

\section{Photoluminescent study}

The fluorescence spectrum of the ligand was recorded in DMF solution by Spex-Fluorolog FL 6500 Spectrofluorimeter furnished with a double grating $0.22 \mathrm{~m}$ Spex 1680 monochromator and a $450 \mathrm{~W}$ Xenon lamp as the excitation source. Quantum yields of the ligands were determined at room temperature by an allied method using anthracene as the standard.

\section{Dynamic light scattering study/Zeta potential analyzer}

The Dynamic light scattering was recorded by using Horiba SZ100 Zetasizer. Zeta Potential was recorded at $25^{\circ} \mathrm{C}$ at an electrode potential of $3.4 \mathrm{~V}$.

\section{RESULTS AND DISCUSSIONS}

The ligand was reddish-brown colour and had a shiny crystalline appearance and the yield was about $85 \%$. The ligand was characterized for physical properties and chemical properties and the results are discussed below. On basis of analytical results, the structure of the ligand was also proposed.

\section{FT-IR Study}

FT-IR spectrum of synthesized ligand was given in Fig. 1. The absorption band at 1620 $\mathrm{cm}^{-1}$ was attributed to the extended vibration of the $v(\mathrm{C}=\mathrm{O})$ group of curcumin. The spectrum of ligand 
showed a band at $1627 \mathrm{~cm}^{-1}$ is due to the azomethine stretching vibration and indicates the formation of ligand. The ligand spectra exhibited a broad band at $3435 \mathrm{~cm}^{-1}$ is the $\mathrm{NH}$ stretching frequency and a band of frequency $3658 \mathrm{~cm}^{-1}$ is due to stretching vibration of $v(\mathrm{O}-\mathrm{H})$. The band at $2920 \mathrm{~cm}^{-1}$ is due to the methylene group stretching in amine.The band at $1031 \mathrm{~cm}^{-1}$ is the $\mathrm{C}-\mathrm{N}$ stretching frequency of ethylenediamine. The band responsible for the rocking vibration of $\mathrm{NH}_{2}$ appears at $616 \mathrm{~cm}^{-1}$. The characteristic peak for the aromatic unsaturation appeared at $1514 \mathrm{~cm}^{-1}$ to $1380 \mathrm{~cm}^{-1}$. The band that appeared at $1450 \mathrm{~cm}^{-1}$ is due to the extending vibration of the $v(\mathrm{C}-\mathrm{O})$ group in $\mathrm{OCH}_{3}$.

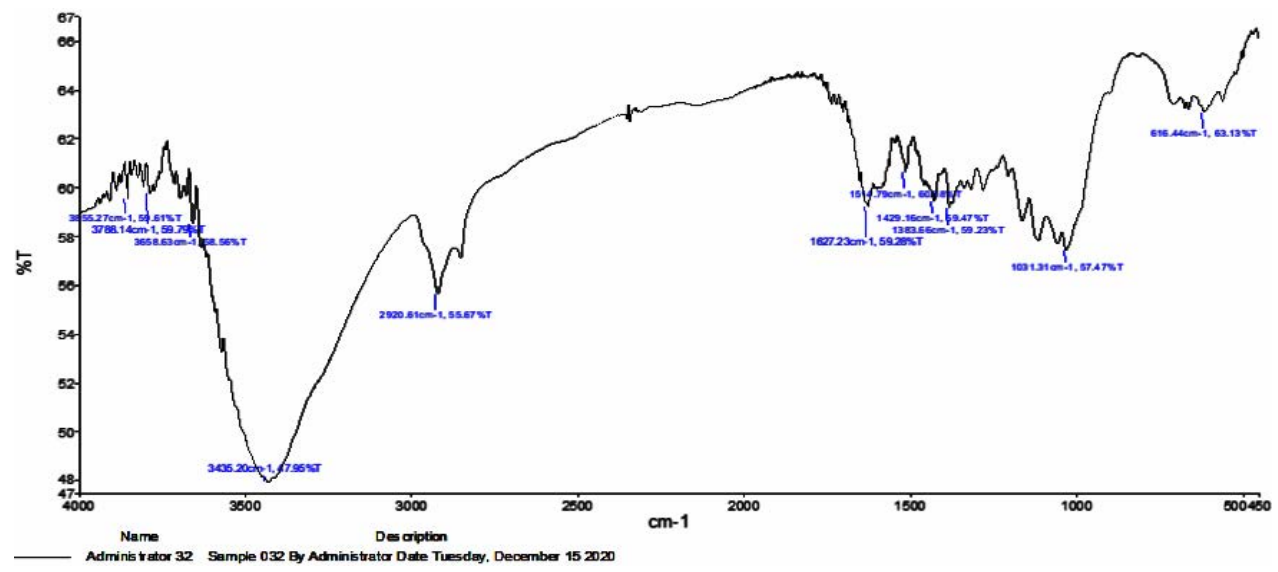

Fig. 1. I. R spectrum of ligand CL

\section{Electronic Spectra}

The UV-Vis absorption spectra of synthesized ligand CL was carried out in one millimolar solution of methanol solvent at the wavelength range $200-800 \mathrm{~nm}$ at $298 \mathrm{~K}$. The UV-Visible spectra were given in Fig. 2. The curcumin derived Schiff base ligand exhibited three absorption bands at $405 \mathrm{~nm}, 261 \mathrm{~nm}$ and $204 \mathrm{~nm}$. The band at $261 \mathrm{~nm}$ refers to the $\pi \rightarrow \pi^{*}$ transitions of the azomethine group while the band at $204 \mathrm{~nm}$ refers to the $\pi \rightarrow \pi^{\star}$ transition of $\mathrm{C}=\mathrm{C}$ bond. The $\lambda_{\text {max }}$ at $405 \mathrm{~nm}$ was due to $n \rightarrow \pi^{*}$ transitions of azomethine nitrogen.

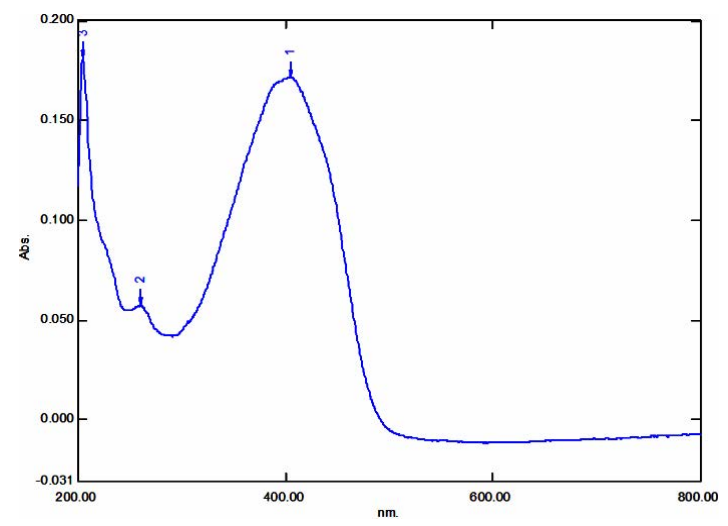

Fig. 2. UV spectrum of ligand CL

\section{${ }^{1} \mathrm{H}$ NMR}

${ }^{1} \mathrm{H}-\mathrm{NMR}$ spectra of the Schiff base ligand $\mathrm{CL}$ was recorded in methanol. The proton NMR spectrum is shown in Fig. 3. The ligand exhibits peaks from $6.7 \mathrm{ppm}$ to $7.5 \mathrm{ppm}$ is due to the aromatic protons. The absence of imine protons in the structure of the ligand was confirmed by the absence of peaks at 8.3 to $8.9 \mathrm{ppm}$. The peak showed at $3.8 \mathrm{ppm}$ is due to the protons in the $\mathrm{OCH}_{3}$ group. The chemical shift value ranges from 4.817 to $4.85 p p m$ indicates the proton signals in the hydroxyl group in phenol. The peak at 1.8ppm is due to the $-\mathrm{NH}_{2}$ protons in the ligand.

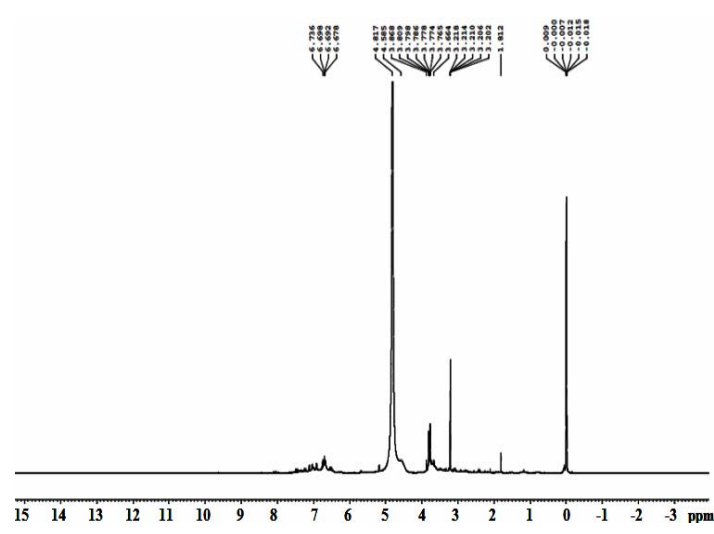

Fig. 3. ${ }^{1} \mathrm{H}$ NMR Spectrum of ligand $\mathrm{CL}$

\section{Melting point determination} was $116^{\circ} \mathrm{C}$.

The melting point of synthesized ligand $\mathrm{CL}$

\section{Molar conductance}

The molar conductance value was 
$16.15 \mathrm{ohm}^{-1} \mathrm{~cm}^{2} \mathrm{~mol}^{-1}$. This low molar conductance value of the ligand $C L$ indicates that the synthesized ligand is non-electrolyte.

\section{Photoluminescence Spectra}

Luminescence has intense application in protein recognition 11-12 optoelectronic devices ${ }^{13}$, ionic liquids ${ }^{14}$ etc. The photoluminescent study is a very sensitive analysis to measure the quality of crystal structure and to identify the sensing ability of materials ${ }^{15}$. Schiff base systems exhibit fluorescence due to intra ligand $\pi \rightarrow \pi^{*}$ transitions ${ }^{16}$. The PL spectrum of ligand $C L$ was recorded at $400 \mathrm{~nm}$ to $800 \mathrm{~nm}$ range and given in Fig. 4. The ligand showed an emission maximum at $475 \mathrm{~nm}$ and $530 \mathrm{~nm}$ when excited at $415 \mathrm{~nm}$ corresponding to $\pi \rightarrow \pi^{*}$ transition and $\mathrm{n} \rightarrow \pi^{*}$ transitions arise due to the unsaturation and conjugation in the ligand CL. From the above transitions observed in the PL spectra, the luminescent behaviour of synthesized ligand was confirmed and it can be used in different areas.

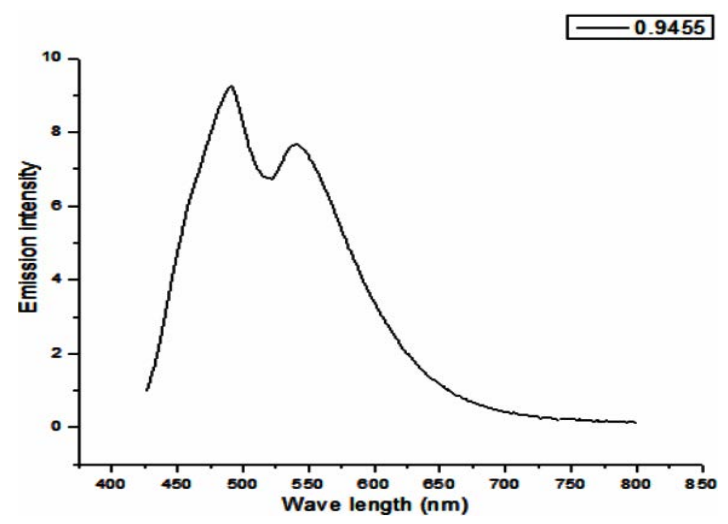

Fig. 4. PL Spectra of ligand CL

Dynamic light scattering Technique

The DLS spectrum is shown in Fig. 5 . The DLS value of ligand CL was $92.1 \mathrm{~nm}$ and confirms that the synthesized ligand was a nano compound.

\section{Zeta potential analysis}

The zeta potential value is shown in Fig. 6 . The ZP value of the synthesized Schiff base ligand $\mathrm{CL}$ was $37.9 \mathrm{mV}$. Zeta potential was recorded at $25^{\circ} \mathrm{C}$ at an electrode potential of $3.4 \mathrm{~V}$. The value suggests that the ligand $C L$ contained highly charged particles and prevents the aggregation of particles due to electric repulsion. The electromobility of the nano compound is $0.000293 \mathrm{~cm}^{2} \mathrm{~N}$.

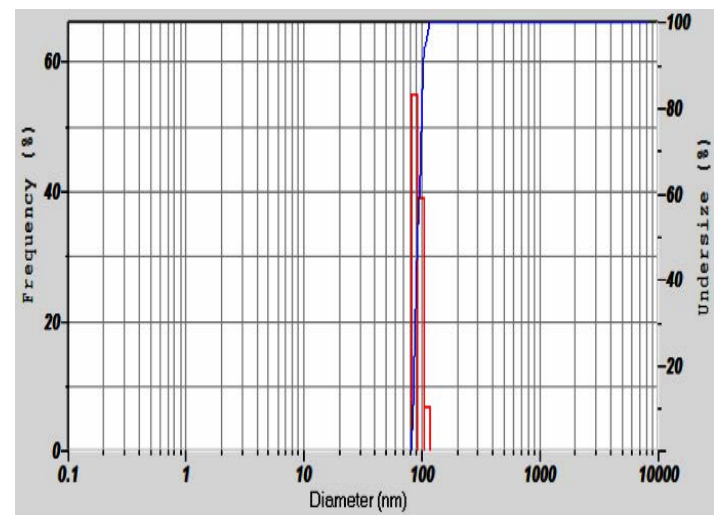

Fig. 5. DLS spectrum of ligand CL

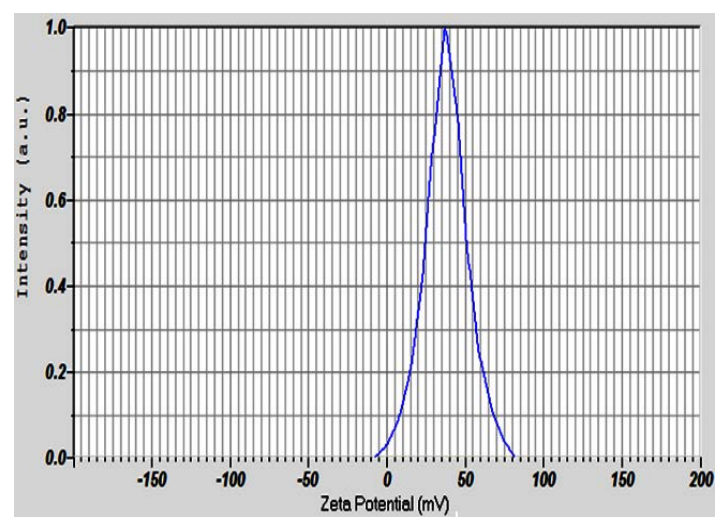

Fig. 6. Zeta potential of ligand CL

\section{Proposed structure of ligand $\mathrm{CL}$}

The spectra studies of FT-IR and UV-Visible confirmed the formation of azomethine group in the ligand. ${ }^{1 H N M R}$ spectrum confirmed aromatic proton, hydroxyl proton, amine proton etc. The molar conductance study showed that the compound is a non-electrolyte in nature. Photoluminescence behaviour of the compound was confirmed and it was due to $\pi-\pi^{\star}$ transition and $n-\pi^{\star}$ transitions of the ligand $C L$ arise due to unsaturation and conjugation in the ligand. By combining the data received from all the above analysis, the proposed structure of Schiff base ligand derived from curcumin and ethylenediamine is shown in Figure 7.<smiles>COc1cc(/C=C/N=C(C=NCCN)/C=C(O)/C=C/c2ccc(O)c(OC)c2)ccc1O</smiles>

Fig. 7. Structure of ligand CL 


\section{CONCLUSION}

A Curcumin derived Schiff base ligand $C L$ was successfully synthesized by the microwave irradiation method. The ligand synthesized was stable at room temperature, completely soluble in hot methanol/DMF, partially soluble in ethanol/DMSO/ acetone and insoluble in water. The spectral studies of FTIR and UV-Visible confirmed the formation of the azomethine group in the ligand. NMR spectrum confirmed aromatic proton, hydroxyl proton, amine proton etc. The molar conductance study showed that the compound is non-electrolyte. The DLS data showed that the ligand synthesized was on a nanometer scale. The luminescent property of the ligand was confirmed by the photoluminescence spectroscopic method and can be used in different sensing applications. Based on the spectral and other analysis data's, ligand structure was also developed.

\section{ACKNOWLEDGMENT}

This research did not receive any specific grant from funding agencies in the public, commercial, or not-for-profit sectors.

\section{Conflicts of interest}

There are no conflicts to declare.

\section{REFERENCES}

1. Hasan, A. M.; Nihad, I. T. Int. J. Inorg. Chem. 2017, 7, 412.

2. Pallikkavil, R.; Ummathur, M. B. Arch. App. Sci. Research., 2012, 4, 2223.

3. Cleiton, M. S.; Daniel, L.S. ; Luzia, V. M. J. Adv. Res. $2011,2,1$

4. Ehab, M. Z.; Ahmed, M.M.; Gehad, G.M. Appl. Organometal. Chem., 2010, 33, 4525.

5. Nighat, F.; Sumit, S.; Ramhari, M. New .J. Chem., 2013, 37, 1145.

6. Luiza, G.; Castelia, C.; Claudia, M. Int. J. Mol. Sci., 2007, 8, 70.

7. Al-Zayd, K M. Arb. J Chem., 2009, 2, 89.

8. Saritha, T. J.; Metilda, P. IJETA., 2018, 5, 5.

9. Abdul, K.; Mohd, S.K.; Shahab, A. A. J. molstruc., 2018, 1167, 261.

10. Porkodi, J.; Arunadevi, A.; Raman, N. J. Biomol. Struc. Dynamic., 2019, 38, 488.

11. Debbie, C. C.; Jordan, T. K.; Stephanie, M.P. Dalton. Trans. 2019, $19,1$.

12. Demasa, J. N.; Crosby, G.A. J. Phy. Chem., 1987, 76, 8.

13. Muhammet, K.; Gökhan, C.; Mehmet, T. Spectrochim. Acta AMol. Biomol. Spectrosc., 2014, 137, 477.

14. Syamchand, S. S.; Sony. J. Lumin., 2015, 165, 190.

15. Zhipeng, L.; Weijiang, H.; Zijian, G. Chem. Soc. Rev., 2013, 42, 1568.

16. Tanmay, C.; Madhuparna, M.; Kazi, S. B. J. coordchem., 2009, 62, 967. 